\title{
Microstructural Features of Austenite Formation in C35 and C45 alloys
}

\author{
V.I. SAVRAN, Y. VAN LEEUWEN, D.N. HANLON, C. KWAKERNAAK, W.G. SLOOF, \\ and J. SIETSMA
}

\begin{abstract}
The microstructural evolution during continuous heating experiments has been studied for two $\mathrm{C}-\mathrm{Mn}$ steels with carbon contents in the range 0.35 to $0.45 \mathrm{wt}$ pct using optical microscopy, scanning electron microscopy (SEM), and electron probe microanalysis (EPMA). It is shown that the formation of the austenitic phase is possible in pearlite as well as in ferrite regions. Thus, a considerable overlap in time of ferrite-to-austenite and pearlite-to-austenite transformations is likely to occur. Another observation that was made during the experiments is that, depending on the heating rate, the pearlite-to-austenite transformation can proceed in either one or two steps. At low heating rates $\left(0.05^{\circ} \mathrm{C} / \mathrm{s}\right)$, ferrite and cementite plates transform simultaneously. At higher heating rates $\left(20^{\circ} \mathrm{C} / \mathrm{s}\right)$, it is a two-step process: first ferrite within pearlite grains transforms to austenite and then the dissolution of the cementite lamellae takes place. Several types of growth morphologies were observed during the experiments. The formation of a finger-type austenite morphology was noticed only for low and intermediate heating rates $\left(0.05^{\circ} \mathrm{C} / \mathrm{s}\right.$ and $\left.20^{\circ} \mathrm{C} / \mathrm{s}\right)$, but not for the heating rate of $300{ }^{\circ} \mathrm{C} / \mathrm{s}$. The formation of this fingertype austenite occurs on pearlite-ferrite grain boundaries and coincides with the direction of cementite plates. The carbon inhomogeneities in the microstructure affect the formation of martensitic/bainitic structures on cooling.
\end{abstract}

DOI: $10.1007 / \mathrm{s} 11661-007-9128-3$

(C) The Minerals, Metals \& Materials Society and ASM International 2007

\section{INTRODUCTION}

HEAT treatment of steels is an everyday routine to obtain materials with desired properties and structures. The first step in the heat-treatment process for the vast majority of commercial steels is austenitization - formation of austenite upon heating from a variety of initial phases. In spite of its importance, there has been little work carried out on the formation of austenite, compared to the huge effort put into studying its decomposition. The major interest toward austenitization was drawn after dual-phase (DP) steels were developed. The DP steels are most commonly used in structural applications where they have replaced more conventional high strength low alloy (HSLA) steels. They were developed to provide high strength formable alloys and offered a significant weight reduction of the final products.

Speich et al. ${ }^{[1]}$ who studied the intercritical annealing of DP steels, distinguished several stages in the ferriteto-austenite transformation. According to Reference 1,

V.I. SAVRAN, Postdoctoral Student, C. KWAKERNAAK, Technical Staff Member, and W.G. SLOOF and J. SIETSMA, Associate Professor, are with the Department of Materials Science and Engineering, Delft University of Technology, 2628 CD, Delft, The Netherlands. Contact e-mail: j.sietsma@tudelft.nl Y. VAN LEEUWEN, Scientist, is with the Nuclear Safety Department, P.O. Box 16191, 2500 BD, The Hague, The Netherlands. D.N. HANLON, Metals Researcher, is with the Corus Research, Development \& Technology, P.O. Box 10000, 1970 CA, IJmuiden, The Netherlands. Manuscript submitted July 26, 2006.

Article published online May 1, 2007. the first step of ferrite-to-austenite transformation consists of the nucleation of austenite $(\gamma)$ at the ferritepearlite interfaces and growth of austenite into pearlite $(\alpha+\theta)$ until the pearlite dissolution is complete. The nucleation of austenite is argued to occur instantaneously, with essentially no nucleation barrier. The rate of growth in this stage is controlled primarily by the rate of carbon diffusion in austenite between adjacent pearlitic cementite $(\theta)$ lamellae, but may also be influenced by diffusion of substitutional elements at low temperatures. ${ }^{[2]}$ At the end of this first step, a highcarbon austenite has been formed, which is not in equilibrium with ferrite $(\alpha)$. The second step of the transformation consists of the growth of this austenite into ferrite to achieve partial equilibrium with ferrite. The lower growth rate of austenite in this step is controlled either by the carbon diffusion in austenite over larger distances or by the manganese diffusion in ferrite. In the final step, very slow final equilibration of ferrite and austenite is achieved by manganese diffusion through austenite. Jayaswal and Gupta, ${ }^{[3]}$ who studied in detail the second and third stages of transformation in HSLA steel, observed that in addition to the growth of austenite from regions of prior pearlite, austenite was also observed to form at the $\alpha-\alpha$ grain boundaries. They were not able to give explanations for this phenomenon, but indicated that the possible reason could be the presence of retained austenite in the starting microstructure. On the other side, Garcia de Andres et al. ${ }^{[4]}$ in their study of the pearlite dissolution in DP steel reported a clear differentiation between the pearlite dissolution process and the $\alpha-\gamma$ transformation. 
An interesting observation that is often reported in relation to the ferrite-to-austenite transformation is the formation of acicular structures. Zel'dovich et al. ${ }^{[5]}$ distinguished three different mechanisms of austenite formation depending on the heating rate. At a very low heating rate (a few degrees per minute) or at a very rapid heating (thousands degrees per second), newly formed austenite grains have an acicular structure, and a structural heredity (the original austenite grain is recovered both in size and crystallographic orientation) is present. It is said that the phenomenon of structural heredity must indicate an ordered mechanism of austenite formation, that is, diffusionless during rapid heating and what is known as the homogeneous mechanism of diffusional transformation during slow heating. Heating at a certain intermediate range results in loss of ordering and in grain refinement. The newly formed austenite grains have more of a rounded shape. ${ }^{[5]}$

The formation of acicular structures during the ferrite-to-austenite transformation was also observed by Jayaswal and Gupta. ${ }^{[3]}$ They noticed that the austenite phase, instead of growing with a planar or nearly planar front, changed into a Widmanstätten structure on both the ferrite-ferrite grain boundaries and on well-advanced ferrite-pearlite (now austenite) interfaces. Law and Edmonds ${ }^{[6]}$ performed studies of the morphology and crystallography of austenite precipitates in Fe- 0.2 pet $\mathrm{C}-1$ pet $\mathrm{V}$ alloy. They noticed that austenite formed on grain boundaries is idiomorphic or allotriomorphic, while that formed on lath boundaries can become acicular by inheriting the lath dimensions. Grain boundary austenite was proven to nucleate in low carbon ferrite with the Kurdjumow-Sachs orientation relationship with one ferrite grain, and to grow predominantly into an adjacent grain with which it was not related. Based on this observation and the general absence of planar facets or sideplate morphologies, they proposed that austenite grows by migration of incoherent interfaces.

This article presents experimental observations obtained during continuous heating experiments of C-Mn steels with 0.35 or $0.45 \mathrm{wt}$ pct carbon, using optical microscopy, scanning electron microscopy (SEM), and electron probe microanalysis (EPMA). The alloys were heated with two different heating rates, $0.05^{\circ} \mathrm{C} / \mathrm{s}$ and 20 ${ }^{\circ} \mathrm{C} / \mathrm{s}$, to different temperatures of the intercritical region and were directly quenched. The effect of the extreme heating rates on the microstructure evolution was studied by heating the samples with $300^{\circ} \mathrm{C} / \mathrm{s}$ to different temperatures within and above the intercritical region. The results of experimental studies for different heating rates on the development of the microstructure during the ferrite-to-austenite transformation focusing on austenite nucleation and growth morphologies are presented and analyzed in this article. Experimental observations to support the idea of probable overlapping of pearlite-to-austenite and ferrite-to-austenite transformations, as observed by Jayaswal and Gupta, ${ }^{[3]}$ are presented together with a possible explanation for this phenomenon.

\section{THEORETICAL BACKGROUND}

\section{A. Driving Force for Nucleation in Hypoeutectoid Steel}

On heating a hypoeutectoid steel from room temperature to a single-phase region, a phase transformation occurs, which consists of two stages, namely, nucleation and growth. The essential driving force behind this transformation is the difference in the Gibbs free energy, $\Delta G$, between the initial and final states. ${ }^{[7]}$ For a transition from phase $i$ to phase $j$ to occur, the condition

$$
\Delta G=G^{j}-G^{i}<0
$$

must be satisfied ( $G^{i}$ and $G^{j}$ are the free energies of the parent and the new phase, respectively).

A schematic representation of the Gibbs free energy $G$ as a function of the carbon concentration is shown in Figure 1(a) at a temperature above the eutectoid temperature of the $\mathrm{Fe}-\mathrm{C}$ system. In this temperature range, two phases, $\alpha$ (ferrite) with composition $\mathrm{C}^{\alpha / \gamma}$ (Figure $1(\mathrm{~b})$, point 1$)$ and $\gamma$ (austenite) with composition $\mathrm{C}^{\gamma / \alpha}$ (point 2), are in equilibrium. The formation of the $\gamma$ phase with the mentioned equilibrium composition leads to a maximum gain in Gibbs free energy $\left(\Delta G^{\max }\right)$. In this case, the newly formed austenite grains have a different composition from the original ferrite phase, and a significant enrichment in carbon must take place.

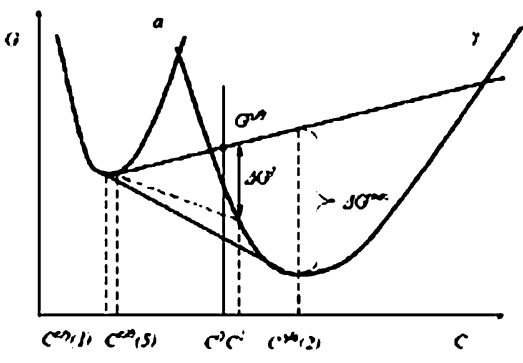

(a)

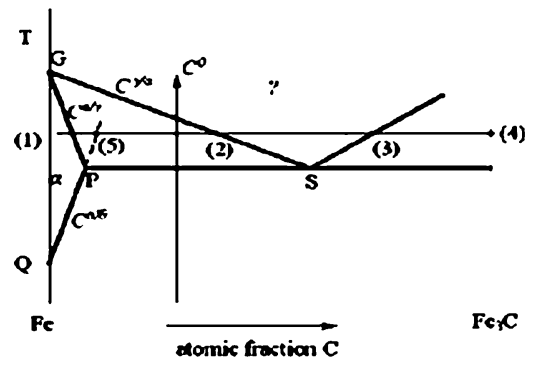

(b)

Fig. 1-Schematic representation of the $(a)$ Gibbs free energy $G$ as a function of the carbon concentration in ferrite $(\alpha)$, austenite $(\gamma)$, and cementite $(\theta)$ at a temperature above $A_{1}$; and $(b)$ metastable $\mathrm{Fe}-\mathrm{C}$ phase diagram, indicating notations for the carbon atomic fractions used throughout the text. Numbers in brackets correspond to figurative points (1) through (5) in Figures 1 and 2. The solid thin lines in (a) represent the common tangent lines between $\alpha-\theta$ and $\alpha-\gamma$. 
From Figure 1(a), it also follows that even though the maximum gain in free energy is achieved for a large carbon enrichment of the $\gamma$ phase (equilibrium condition), some decrease in the Gibbs free energy, even though of a smaller value, is also realized with the formation of the $\gamma$ phase with lower carbon content (for example, $\Delta G^{1}$, a situation in which the system departs from the thermodynamic equilibrium). Thus, even though with the formation of low-carbon austenite the gain in Gibbs free energy is smaller compared to the equilibrium value $\left(\Delta G^{1}<\Delta G^{\max }\right)$, this process is nevertheless thermodynamically possible. By low-carbon austenite, the austenite with a carbon content less than equilibrium according to the phase diagram is understood, and not a carbon-free austenite. Some degree of enrichment does have to take place and the nucleation and growth will be stimulated in carbon-rich areas or in their vicinity.

\section{B. Temperature Range 1: $A_{1}<T<A_{3}$}

The changes in the microstructure of steel on heating can in part be understood in terms of the $\mathrm{Fe}-\mathrm{C}$ phase diagram (Figure 1(b)). At room temperature and normal pressure, the microstructure of carbon hypoeutectoid steel after slow cooling consists of ferrite and pearlite. Upon heating the steel from room temperature to the $A_{3}$ temperature, two different situations can be distinguished. The first one is related to the formation of austenite within the pearlite phase at the $\alpha / \theta$ interface, as the one schematically represented in Figure 2(b), and is described as

$$
\alpha_{\mathrm{C}^{\alpha / \theta}}+\theta \rightarrow \alpha_{\mathrm{C}^{\alpha / \gamma}}+\gamma_{\mathrm{C}^{\gamma / \alpha}}
$$

where $C^{\alpha / \theta}$ and $C^{\alpha / \gamma}$ are the equilibrium carbon concentrations in ferrite, changing with temperature according to lines $Q P$ and $P G$, respectively (Figure $1(\mathrm{~b})) ; \mathrm{C}^{\gamma / \alpha}$ is the equilibrium carbon concentration in austenite, changing according to line $S G$; and $\theta$ is cementite and is considered to be of a constant composition.

It is known that the velocity of the phase boundary can be considered in first approximation inversely related to the carbon concentration difference on it. ${ }^{[8]}$ For the value of this difference, the concentration should change to form a new phase. The carbon difference on the $\alpha-\gamma$ grain boundaries is much less than on the $\gamma-\theta$ grain boundary; thus, austenite can be expected to grow much faster in the ferrite phase than in the cementite phase.

Figure 2(b) is a one-dimensional representation of the planar geometry. In this case, the interface movement is controlled by the diffusion of carbon through the austenite phase. The situation at a triple line between cementite, ferrite, and austenite is not considered as the diffusion distances become negligible, and it will not be a limiting factor for the transformation.

The second situation is related to the possible formation of austenite on ferrite-ferrite grain boundaries (Figure 2(c)) and can be described as

$$
\alpha_{\mathrm{C}^{\alpha / \theta}} \rightarrow \alpha_{\mathrm{C}^{\alpha / \gamma}}+\gamma_{\mathrm{C}^{\gamma / \alpha}}
$$

From the Fe-C phase diagram (as the one shown in Figure 1(b)), it is seen that the carbon concentration in ferrite decreases with increasing temperature. This will lead to austenite nucleation at the $\alpha-\alpha$ grain boundaries. Thus, not only does the carbon of cementite play a role in the formation of austenite, but so does the carbon rejected from the $\alpha$-solid solution. On the other hand, due to the difference in carbon solubility at the $\alpha / \theta$ and $\alpha / \gamma$ grain boundaries, a concentration gradient within the ferrite phase is present $\left(C^{\alpha / \theta}>C^{\alpha / \gamma}\right.$, Figure 2(c)). This creates the driving force for carbon diffusion toward the $\alpha-\gamma$ grain boundary.

The subsequent growth of the austenite nuclei involves the removal of carbon from cementite with its

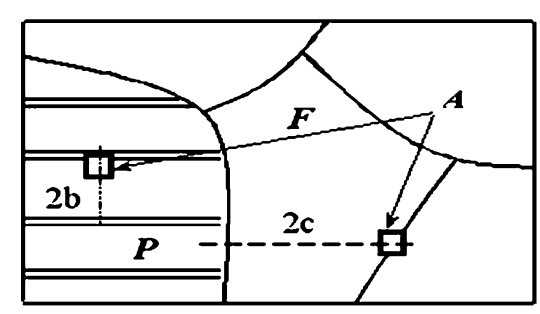

(a)

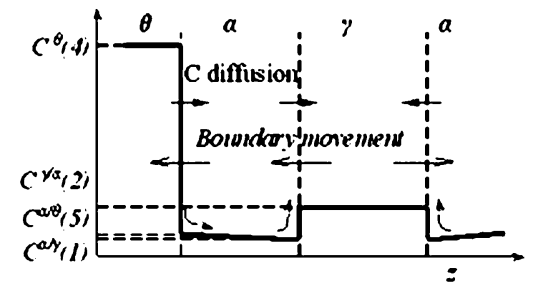

(c)

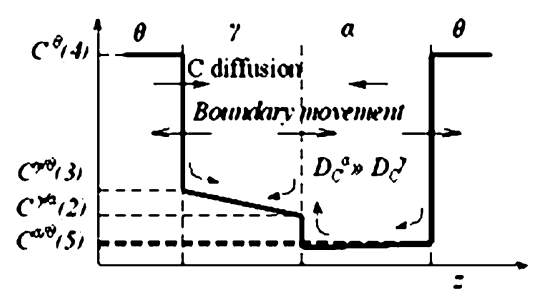

(b)

Fig. 2-Schematic view of the microstructure $(a)$ and variation of the carbon content across $(b)$ the cementite-austenite-ferrite and $(c)$ the ferriteaustenite-ferrite boundaries. $\mathrm{F}=$ ferrite, $\mathrm{A}=$ austenite, and $\mathrm{P}=$ pearlite. 
diffusion into the not-transformed ferrite in order to "feed" carbon to austenite at the $\alpha / \gamma$ interface. The velocity of the $\alpha-\gamma$ grain boundary movement depends on how fast the carbon is supplied to it and, consequently, on the diffusion path length. This leads to the notion that ferrite within the pearlitic phase will transform much faster than proeutectoid ferrite.

Taking all of the aforementioned into account, it is possible to assume that the nucleation of austenite grains in pearlite and in proeutectoid ferrite can both occur; however, the transformation will proceed at a much higher rate in the pearlite phase than in proeutectoid ferrite due to the shorter diffusion distances and the surplus of carbon that is available from the dissolving cementite plates.

\section{Temperature Range 2: $T>A_{3}$}

The transformation that takes place at temperature $T>A_{3}$ can be described as

$$
\alpha_{\mathrm{C}^{\alpha / \gamma}}+\gamma_{\mathrm{C}^{\gamma / \alpha}} \rightarrow \gamma_{\mathrm{C}^{0}}
$$

where $\mathrm{C}^{0}$ is the average carbon concentration in the alloy, and therefore also the austenite composition under equilibrium conditions after the transformation is completed (above $A_{3}$ ).

Upon further heating of the sample in the temperature range $A_{1}<T<A_{3}$, the $\alpha \rightarrow \gamma$ transformation at conditions close to equilibrium proceeds most probably by diffusional growth. The transformation completes above the $A_{3}$ temperature. In alloys with low carbon content and thus a low amount of pearlitic phase present, nucleation on the ferrite-ferrite grain boundaries can take place. For the alloys with high pearlitic volume fractions, transformation proceeds via the growth from the already existing austenitic areas (mainly former pearlite grains) into proeutectoid ferrite.

\section{EXPERIMENTAL PROCEDURE}

In order to examine the evolution of the microstructure during continuous heating in C35 and C45 steels, a set of interrupted heating experiments was performed using a Bähr 805A/D dilatometer (Hüllhorst, Germany). Typical micrographs of the initial microstructures for C35 and C45 alloys are shown in Figure 3. The micro- structures consist of ferrite and pearlite mixture with different phase volume fractions. Chemical compositions of the experimental alloys are shown in Table I. The Ac1 and Ac3 temperatures for studied alloys are presented in Table II. For the results that will be presented in this article, the differences in chemical compositions between studied alloys do not play a significant role.

The samples, with a diameter of $5 \mathrm{~mm}$ and a length of $10 \mathrm{~mm}$, were heated using a high-frequency induction coil with heating rates $0.05^{\circ} \mathrm{C} / \mathrm{s}$ and $20^{\circ} \mathrm{C} / \mathrm{s}$ to different temperatures within the ferrite + pearlite-to-austenite transformation region and directly quenched with cooling rates in the range of $700{ }^{\circ} \mathrm{C} / \mathrm{s}$ to $750{ }^{\circ} \mathrm{C} / \mathrm{s}$. A thermocouple, spot welded on the sample, was used to control the temperature during the test. Samples for metallographic examinations were ground, polished, and etched with a 2 pct Nital cleaning agent and examined under an optical microscope.

The secondary electron images were produced with a LEO 438VP scanning electron microscope fitted with a tungsten filament. Samples for SEM measurements were first mechanically polished to $1 \mu \mathrm{m}$ and then electrolytically polished using electrolyte that contained $400 \mathrm{~mL}$ 99 pet 2-bytoxyethanol with $20 \mathrm{~mL} \mathrm{HClO}_{4}$ (hydrogen peroxide $30 \mathrm{pct}$ ).

The composition profiles of the samples were determined using EPMA. On the cross sections prepared from the samples, $0.5-\mu \mathrm{m}$ equidistant points were selected along lines defined in backscattered electron images. The measurements were performed with a JEOL* JXA

*JEOL is a trademark of Japan Electron Optics Ltd., Tokyo.

8900R wavelength-dispersive/energy-dispersive combined microanalyzer, operated with a focused electron beam of $15 \mathrm{keV}$ and $25 \mathrm{nA}$. These electron beam conditions were a compromise between sufficient spatial resolution and intensity of $\mathrm{C} K_{\alpha}$ radiation. Wavelength dispersive spectrometry was employed to record the C $K_{\alpha}, \mathrm{Si} K_{\alpha}, \mathrm{Cr} K_{\alpha}, \mathrm{Mn} K_{\alpha}$, and $\mathrm{Cu} K_{\alpha}$ intensities simultaneously. A W/Si X-ray reflective multilayer with a $2 d$ spacing of $9.80 \mathrm{~nm}$ was used for selecting the C $K_{\alpha}$ radiation, a (100)-TAP was used for selecting Si $K_{\alpha}$, a (002)-PET for Cr $K_{\alpha}$, and a (200)-LiF crystal for Mn $K_{\alpha}$ and $\mathrm{Cu} K_{\alpha}$ radiation. The peak intensity for a single spot on the specimen was determined from measuring the

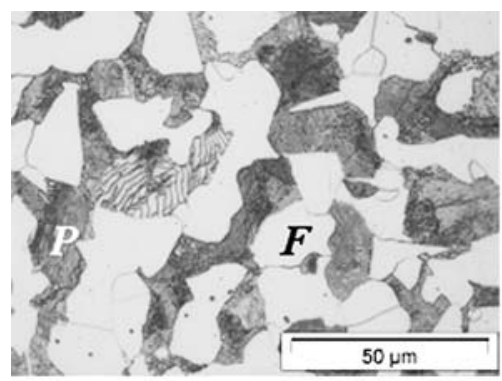

(a)

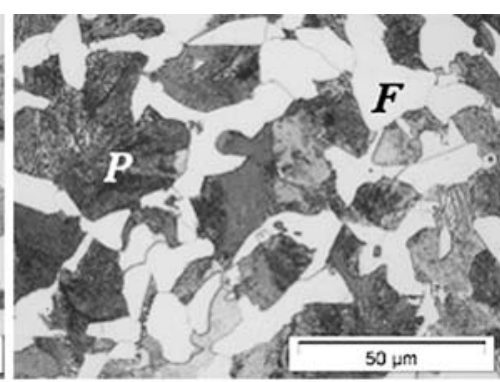

(b)

Fig. 3-Initial microstructures for $(a) \mathrm{C} 35$ and $(b) \mathrm{C} 45 . \mathrm{F}=$ ferrite (white) and $\mathrm{P}=$ pearlite (dark). 
Table I. Composition of the Experimental Alloys in Weight Percentages

\begin{tabular}{lcccccccrrr}
\hline Alloy & $\mathrm{C}$ & $\mathrm{Mn}$ & $\mathrm{Si}$ & $\mathrm{Cu}$ & $\mathrm{Cr}$ & $\mathrm{Ni}$ & $\mathrm{Mo}$ & $\mathrm{Sn}$ & $\mathrm{P}$ & $\mathrm{S}$ \\
\hline C35 & 0.364 & 0.656 & 0.305 & 0.226 & 0.177 & 0.092 & 0.016 & 0.017 & 0.014 & 0.021 \\
C45 & 0.468 & 0.715 & 0.257 & 0.231 & 0.193 & 0.144 & 0.017 & 0.013 & 0.002 & 0.031 \\
\hline
\end{tabular}

Table II. Ac1 and Ac3 Temperatures for C35 and C45 Alloys for Two Different Heating Rates 0.05 and $20{ }^{\circ} \mathrm{C} / \mathrm{s}$

\begin{tabular}{lcccc}
\hline & $\begin{array}{c}\mathrm{Ac} 1,{ }^{\circ} \mathrm{C} \\
\text { Alloy }\end{array}$ & $\begin{array}{c}\mathrm{Ac} 1,{ }^{\circ} \mathrm{C} \\
2{ }^{\circ} \mathrm{C} / \mathrm{s}\end{array}$ & $\begin{array}{c}\mathrm{Ac} 3,{ }^{\circ} \mathrm{C} \\
0.05{ }^{\circ} \mathrm{C} / \mathrm{s}\end{array}$ & $\begin{array}{c}\mathrm{Ac} 3,{ }^{\circ} \mathrm{C} \\
20{ }^{\circ} \mathrm{C} / \mathrm{s}\end{array}$ \\
\hline $\mathrm{C} 35$ & 735 & 760 & 800 & 860 \\
$\mathrm{C} 45$ & 730 & 755 & 770 & 810 \\
\hline
\end{tabular}

number of counts during 4 minutes. The background intensities of $\mathrm{C} K_{\alpha}$, Si $K_{\alpha}, \mathrm{Cr} K_{\alpha}, \mathrm{Mn} K_{\alpha}$, and $\mathrm{Cu} K_{\alpha}$ were determined similarly at the same spot. The background intensity of C $K_{\alpha}$ was measured separately on a pure $\alpha-\mathrm{Fe}$ reference. The surface of the specimen was decontaminated 30 seconds prior to and during each measurement using an air jet. This procedure removes any carbonaceous surface contamination at the measurement location. The composition at each analysis location of the sample was determined using the X-ray intensities of the constituent elements after background correction relative to the corresponding intensities of reference materials, i.e., $\theta-\mathrm{Fe}_{3} \mathrm{C}^{[\mathrm{b}]}$ for $\mathrm{C}$, and the pure elements for $\mathrm{Si}$, $\mathrm{Cr}, \mathrm{Mn}$, and $\mathrm{Cu}$, respectively. The thus obtained intensity ratios were processed with a matrix correction program CITZAF based on the $\Phi(\rho z)$ method $^{[10]}$ to compute the composition with the matrix element $\mathrm{Fe}$ taken as balance. The carbon concentrations determined are accurate within $0.03 \mathrm{wt}$ pct, including the background error. ${ }^{[9]}$

\section{RESULTS}

\section{A. Nucleation}

Figures 4 and 5 show typical optical and SEM images from the interrupted heating experiments. In these down-quenched samples, martensite islands reveal the locations of the austenite grains. Two interesting observations can be made. The first observation is related to the nucleation of the new austenite grains, which takes place predominantly in pearlite areas that are rich in carbon (Figures 4(a) and (b)). Depending on the heating rate, this process can take place in one or two steps. At a very low heating rate, $0.05{ }^{\circ} \mathrm{C} / \mathrm{s}$, there is no essential delay between the ferrite-to-austenite transformation and the cementite dissolution within the pearlite grain. Figures 4(a) and 5(b) show that no inhomogeneities are present in the martensite phase that was austenite prior to cooling. Figure 5(a) (area marked with oval) shows an austenite grain nucleated on the ferrite-pearlite grain boundary. The growth of the newly formed austenite grain is not planar and the position of austenite "fingers" coincides with the direction and position of the cementite lamellae, which are rich in carbon.

A completely different situation was observed in the case when the heating rate was $20^{\circ} \mathrm{C} / \mathrm{s}$. A clear delay in the cementite dissolution in comparison to the ferrite-toaustenite transformation resulted in a time-step difference between the two processes. ${ }^{[4]}$ A closer look using SEM (Figure 4(b)) reveals a partially transformed pearlite grain in which the cementite is not completely dissolved in martensite, which was austenite at high temperatures prior to quenching.

The second interesting observation is related to the nucleation of austenite on the ferrite-ferrite grain boundaries: at a triple point (arrow in Figure 5(a)) and a grain boundary (Figure 5(b)). The austenite nuclei have a classical cuplike shape and appear at the very early stages of the transformation. Thus, two transformations, pearlite-to-austenite and ferrite-to-austenite, appear to overlap. The degree to which the two

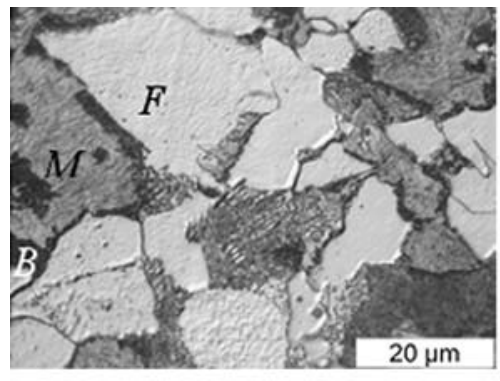

(a)

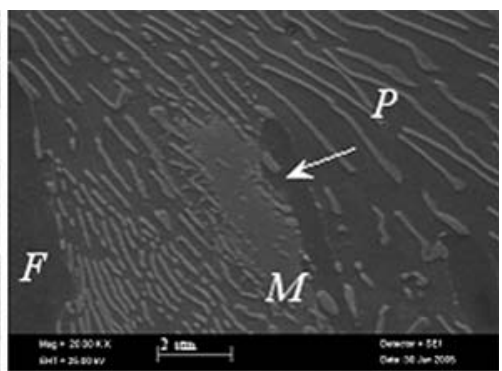

(b)

Fig. 4-Typical micrographs from the interrupted heating experiments. (a) Optical micrograph of the C35 alloy heated with the heating rate of $0.05{ }^{\circ} \mathrm{C} / \mathrm{s}$ to $745^{\circ} \mathrm{C}$ (close to the end of the pearlite-to-austenite transformation) and (b) SEM micrograph of the C45 alloy heated with the heating rate of $20^{\circ} \mathrm{C} / \mathrm{s}$ to $765^{\circ} \mathrm{C}$ (middle of a pearlite-to-austenite transformation). The arrow indicates a pearlite grain that was transformed into austenite on heating and subsequently into martensite on cooling. In this grain, the cementite plates are still visible and, in some cases, partially dissolved. $\mathrm{F}=$ ferrite, $\mathrm{M}=$ martensite, and $\mathrm{P}=$ pearlite. 


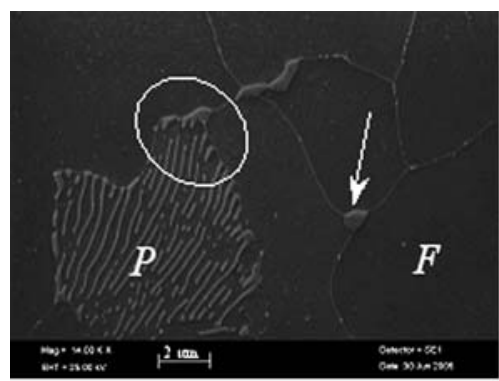

(a)

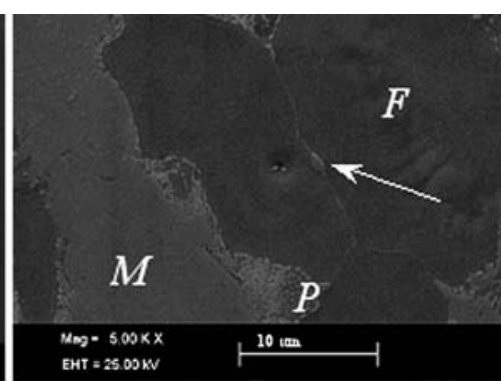

(b)

Fig. 5-SEM micrographs of the $\mathrm{C} 35$ alloy, heated with $0.05{ }^{\circ} \mathrm{C} / \mathrm{s}$ to $(a) 740{ }^{\circ} \mathrm{C}$ (start of the pearlite-to-austenite transformation) and $(b) 745{ }^{\circ} \mathrm{C}$ (close to the end of the pearlite-to-austenite transformation). The arrows indicate the nucleation of austenite at a triple point (a) and a ferriteferrite grain boundary (b). $\mathrm{F}=$ ferrite, $\mathrm{M}=$ martensite, and $\mathrm{P}=$ pearlite.

processes overlap cannot be established from the present experiments.

Figure 6 shows the distribution of the alloying elements across the austenite nuclei on the ferrite-ferrite grain boundary similar to the one shown in Figure 5(b). The carbon concentration across the austenite nucleus region varies significantly: from approximately $0.01 \mathrm{wt}$ pet in the ferrite phase and up to 0.27 pet in the austenite nuclei. Other alloying elements ( $\mathrm{Si}, \mathrm{Cr}$, $\mathrm{Mn}$, and $\mathrm{Cu}$ ) do not show any significant variations in concentrations.

\section{B. Growth Morphologies}

Several types of growth morphologies were observed during the experiments. Acicular (finger) type growth is spotted on the pearlite-ferrite grain boundaries (Figure 7). New austenite grains nucleate on the grain boundary and grow into the neighboring ferrite grain, most likely inheriting the lath dimensions. This type of growth is only detected on pearlite laths being perpendicular to the ferrite/pearlite grain boundary and is not present if the laths are parallel to it. In the latter case, the formation of a bainitic structure on cooling takes place (Figures 7 and 8). This bainite was austenite at

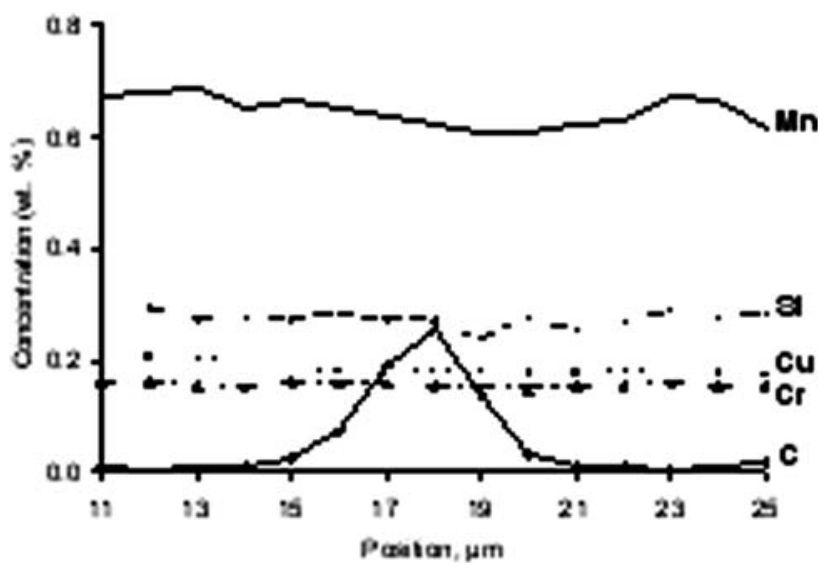

Fig. 6-Alloying element distribution across austenite nuclei formed on ferrite-ferrite grain boundary (C35 alloy). The maximum of the carbon concentration corresponds to the middle of austenite nuclei. The low level of the carbon concentration corresponds to the ferrite phase. higher temperatures prior to quenching. The bainitic phase is clearly visible in the vicinity of former pearlite grains (martensite after quenching), is black in color, and lies along the grain boundaries.

Figure 9 shows the distribution of the alloying elements across the fingers, as determined by EPMA. Similar to Figure 6, the only diffusing element is carbon; the other elements $(\mathrm{Si}, \mathrm{Cr}, \mathrm{Mn}$, and $\mathrm{Cu}$ ) show no or negligible variations in concentrations. The carbon content varies from approximately $0.2 \mathrm{wt}$ pct between the fingers to approximately $0.8 \mathrm{wt}$ pct inside the finger.

The micrographs showing the effect of the extreme heating rate $\left(300{ }^{\circ} \mathrm{C} / \mathrm{s}\right)$ and different holding times on the microstructure evolution are shown in Figure 10. At $770{ }^{\circ} \mathrm{C}$ and holding time 1 second, the microstructure is highly inhomogeneous and consists of ferrite (white areas), bainite (black areas), and martensite matrix (gray areas). The black areas form a continuous network and reproduce the original grain size. The ferritic phase lies along these black lines, presumably the former grain boundaries.

Figure 11 shows the distribution of alloying elements along the line T-T (Figure 10(a)). Alloying elements ( $\mathrm{Si}, \mathrm{Cr}, \mathrm{Mn}$, and $\mathrm{Cu}$ ) do not show significant variations in concentrations. In contrast, the carbon concentration in the black phase is remarkably low: around $0.2 \mathrm{wt}$ pct. In the rest of the sample, the carbon content is approximately $0.4 \mathrm{wt}$ pct, which is about the average carbon content in the sample.

With increasing the holding time to 10 seconds (Figure 10(b)), the structure tends to become more homogeneous and the amount of ferritic phase first decreases and eventually almost disappears at a holding time of 60 seconds (Figure 10(c)). The temperature of $770{ }^{\circ} \mathrm{C}$ corresponds to the austenite area in the $\mathrm{Fe}-\mathrm{C}$ phase diagram. At higher overheating $\left(900{ }^{\circ} \mathrm{C}\right)$ and short holding time (1 second), the microstructure is as well highly inhomogeneous and consists of a martensitic matrix (gray areas) and a bainitic phase (black areas) forming a continuous network (Figure 10(d)).

\section{DISCUSSION}

It has been known for a long time that the situation during forming of austenite is much different from the 


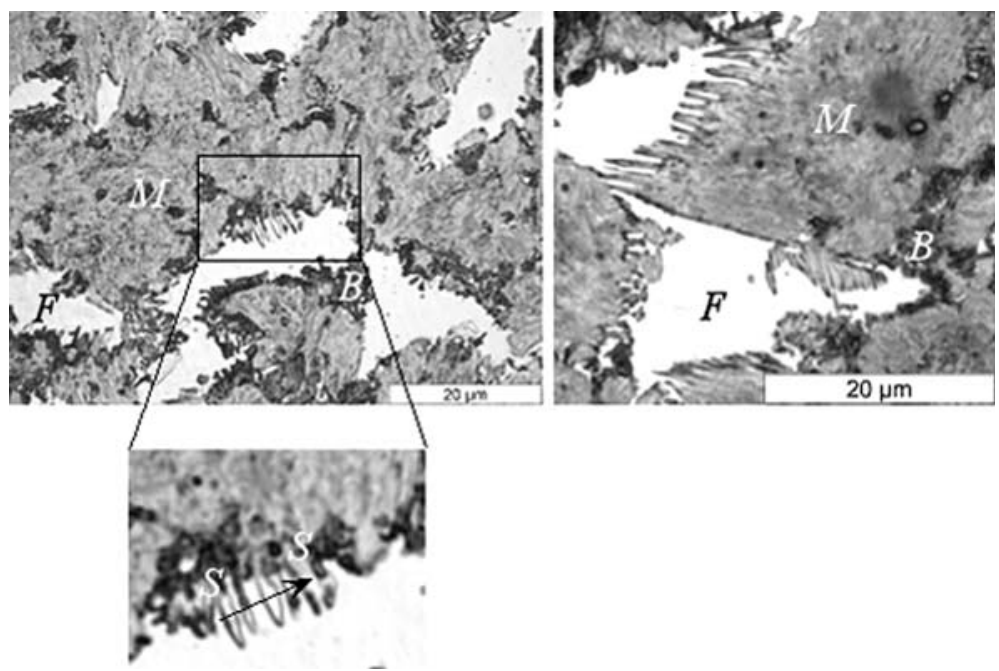

Fig. 7-Examples of acicular growth morphologies as found in C35 and C45 alloys. The arrow (S-S) indicates the direction of EPMA measurement (Fig. 9).

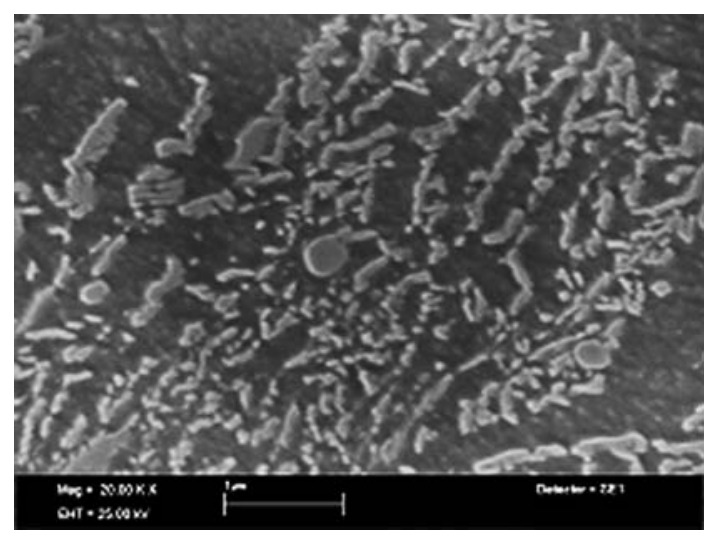

Fig. 8-SEM micrograph of the bainite structure.

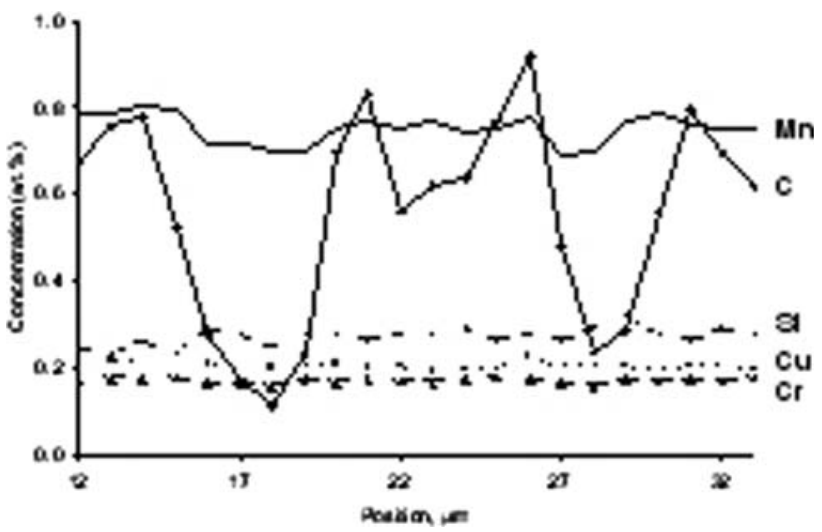

Fig. 9-Alloying element distribution across the fingers in the $\mathrm{C} 45$ alloy (Fig. 7). The maximum of the carbon concentration corresponds to the fingers and the minimum between them.

transformation upon cooling. As the temperature is raised into the austenite region, the driving force for transformation increases (this is the difference in the free energy of the product, austenite, and the starting microstructure, such as pearlite or ferrite). Also, with increasing temperature, the atomic mobility increases. Thus, the rate of austenite formation increases with increasing temperature. Because both the thermodynamic driving force for the formation of austenite and the atomic mobility become larger with higher temperatures, both the rate of nucleation and the rate of growth continually increase with increasing temperature.

\section{A. Nucleation}

Above the $A_{1}$ temperature, the ferrite + pearlite phase mixture, which was stable at lower temperatures, becomes unstable. The system will try to decrease its free energy by creating austenite, and consequently, an austenite-ferrite interface is formed. The essential driving force behind this transition is the difference in the Gibbs free energy between the initial and final states. As was already shown in Section II, maximum gain in free energy is achieved for a large carbon enrichment of the $\gamma$ phase. Some decrease in the Gibbs free energy, even though of a smaller value, is also possible with the formation of the $\gamma$ phase with a lower than equilibrium carbon content (for example, $\Delta G_{1}$ in Figure 1(a)). In both cases, nevertheless, the nucleation and growth is stimulated in carbon-rich areas or their vicinity, because some enrichment of austenite phase has to take place. There are two possible sources of carbon. First of all, these are the pearlitic areas, which have lamellar structures, consisting of alternating ferrite (low in carbon) and cementite (high in carbon) plates (Figures 2(a) and (b)). The second is the proeutectoid ferrite itself, because $\mathrm{C}_{\alpha / \gamma}(1)<C_{\alpha / \theta}$ (5) (Figure 2(c)). Hence, it follows that, for the austenitic nucleus formed on the boundary of ferrite grains, contact with cementite is not necessary. The decreasing equilibrium $\mathrm{C}$ content with increasing temperature in the ferritic phase is in itself a direct source of carbon. After supplying carbon to 


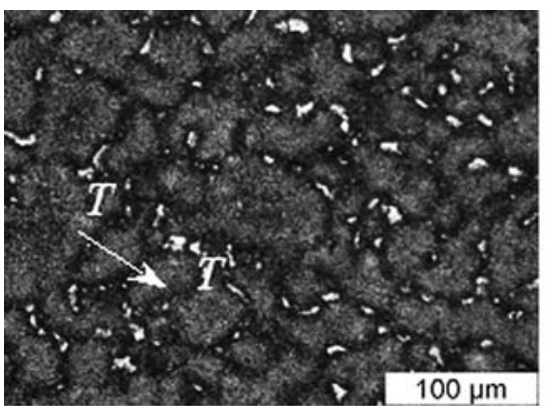

(a)

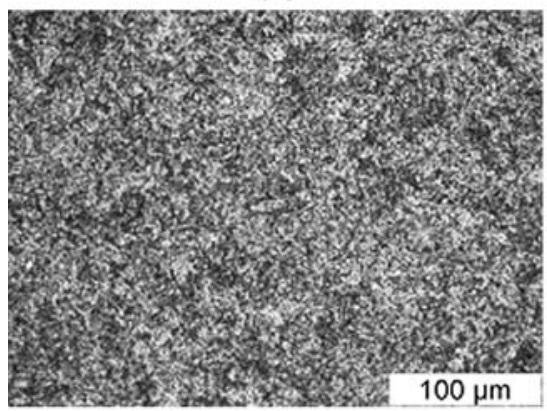

(c)

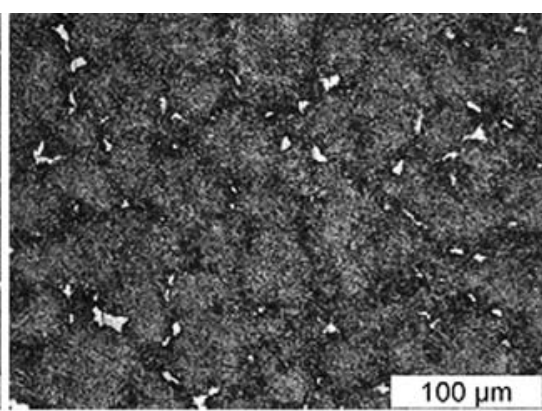

(b)

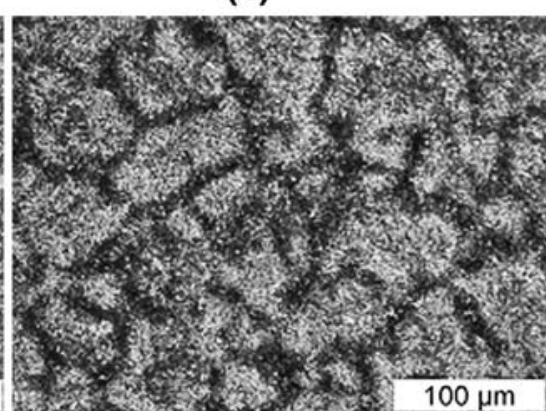

(d)

Fig. 10-Typical micrographs from the interrupted heating experiments of the $\mathrm{C} 45$ alloy heated with $300{ }^{\circ} \mathrm{C} / \mathrm{s}$ to $(a) 770{ }^{\circ} \mathrm{C}, 1 \mathrm{~s} ;(b) 770{ }^{\circ} \mathrm{C}$, $10 \mathrm{~s} ;(c) 770{ }^{\circ} \mathrm{C}, 60 \mathrm{~s}$; and $(d) 900{ }^{\circ} \mathrm{C}, 1 \mathrm{~s}$. The arrow (T-T) indicates the direction of EPMA measurement (Fig. 11). Ferrite $=$ white, martensite $=$ gray, and bainite $=$ black.

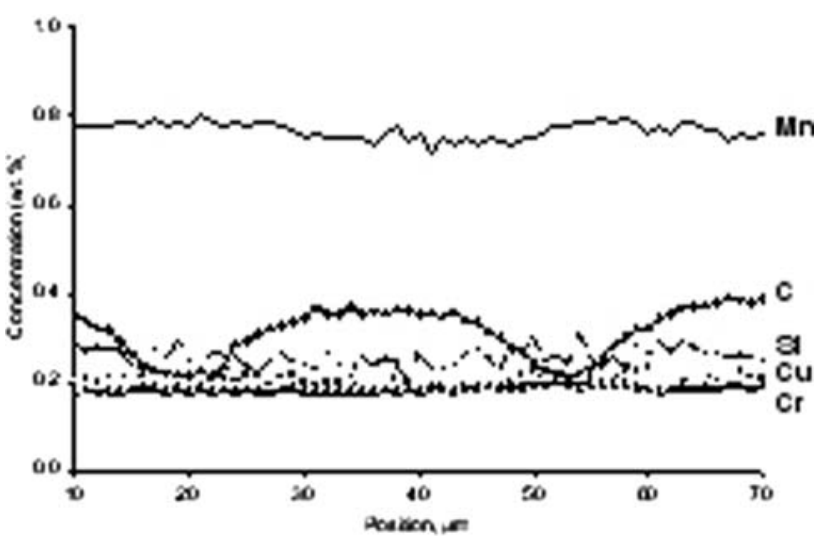

Fig. 11-Alloying element distribution along the line T-T in the C45 alloy (Fig. 10(a)). The minimum of the carbon concentration corresponds to the position of the black phase (bainite).

austenite, ferrite is, in its turn, resupplied with carbon by the dissolution of cementite plates, thus creating a constant driving force for the carbon diffusion toward the austenite-ferrite interface (Figure 2).

During the experiments, both types of nucleation were observed for the $0.05{ }^{\circ} \mathrm{C} / \mathrm{s}$ heating rate and only one type of nucleation (within the pearlitic areas) for the $20^{\circ} \mathrm{C} / \mathrm{s}$ heating rate. The EPMA measurements show a significant variation in carbon content in austenite nucleated on the ferrite-ferrite grain boundaries (about $0.27 \mathrm{wt}$ pct, low-carbon austenite) and the one nucleated on pearlite-ferrite boundaries (around $0.8 \mathrm{wt}$ pct, high-carbon austenite, which is close to the equilibrium value at temperature just above $A_{1}$ ). The possible presence of carbides on ferrite-ferrite grain boundaries prior to transformation, which could stimulate the austenite nucleation, is doubtful. First of all, they were not observed in the initial microstructures, and second, their presence on ferrite-ferrite grain boundaries would lead to austenite nucleation on them for all heating rates, which was not the case. This observation indicates the importance of carbon diffusion during the transformation to the growing austenite phase. At the higher heating rates, there is not enough time for carbon to diffuse, so the austenite nucleation takes place only on ferrite-pearlite boundaries in the vicinity of the carbon source.

Obviously, the diffusion of carbon is not an infinitely fast process. The indication of the delay in cementite dissolution compared to the austenite formation is clearly seen in Figure 4(b) (the grain indicated by an arrow). The pearlitic ferrite undergoes the transformation to austenite at higher temperatures, and upon further quenching, it transforms into martensite. At the same time, the cementite plates are still visible within martensite. Similar observations were made in References 1,2 , and 11 through 14 . They noticed that new grains of austenite grow along the plates of ferrite in a pearlite colony and expand to replace the ferrite in the colony. The cementite plates do dissolve in this austenite, but the austenite grains grow into ferrite at a faster rate than that at which the cementite plates dissolve. This residual cementite is eventually first thin and then spheroidizes and dissolves completely in austenite, depending on the carbon content and temperature. This points out the time difference between austenite formation and cementite dissolution. Thus, the main 
difference between the pearlite formation on cooling and pearlite transformation on heating is that, on cooling, the ferrite and cementite plates grow together, whereas on heating, it is a two-step process and thus pearlite should be considered as consisting from two different phases: ferrite and cementite.

\section{B. Growth Morphologies}

The carbon diffusion process, the rate of which increases with temperature, plays an important role in the occurrence of growth morphologies. As was indicated in Section IV.B, several types of growth morphologies were observed. The finger-type austenite growth morphologies (Figure 7) were spotted growing from the former pearlitic areas into neighboring proeutectoid ferrite grains. The average carbon concentration within the fingers is around $0.8 \mathrm{wt}$ pct, indicating that the fingers grow from the carbon-rich areas. Thus, it can be argued that the formation of the fingers coincides with the position of former cementite plates that were perpendicular to the grain boundary. After pearlite transformation to austenite is completed, the newly formed "pearlitic" austenite is inhomogeneous in composition, the carbon content being highest at the location of pre-existing cementite plates. ${ }^{[1,15]}$ Thus, the driving force at these grain boundaries is highly inhomogeneous. At low heating rates, which correspond to a low degree of overheating, the driving force for ferrite-to-austenite transformation is not high, and it is energetically more favorable for austenite nuclei to grow with minimum surface energy. Minimal surface energy is secured by an orientation relationship between austenite and ferrite. In the case of finger-type growth, the coherent broad sides should have a relatively low interfacial energy, whereas the incoherent tip would have a much higher interfacial energy. The presence of an orientation relationship between ferrite and austenite was shown by Law and Edmonds, ${ }^{[6]}$ who determined that the austenite was always within $15 \mathrm{deg}$ of a Kurdjumow-Sachs orientation relationship:

$$
(110)_{\mathrm{bcc}} / /(111)_{\mathrm{fcc}},[1 \overline{1} 1]_{\mathrm{bcc}} / /[0 \overline{1} 1]_{\mathrm{fcc}}
$$

For the bcc-fcc phase combination, these are the only planes that are more or less identical in each crystal, and by choosing the correct orientation relationship, it is possible for a low energy coherent or semicoherent interface to be formed. There are, however, no other sets of planes of good matching and the austenite plate is thus bounded by the incoherent interface. It is known that an incoherent interface has a much higher mobility than a coherent one. ${ }^{[16]}$ The incoherent interface will move as fast as diffusion allows and the growth will take place under diffusion-controlled mode. At the very fast heating rates, as the ones shown in Figure 10, "fingers" of austenite were not formed. This can be explained by the lack of time for the diffusion to proceed because of the relatively high driving forces for ferrite-to-austenite transformation.
In the places where the cementite plate direction is not perpendicular to the grain boundary, the formation of a "black etching" structure on cooling was observed (for example, Figures 7 and 10). The EPMA measurements (Figure 10(a), line T-T, and Figure 11) show that the black phase has a lower carbon content (around $0.2 \mathrm{wt}$ pct) compared to the rest of the sample, which is around $0.4 \mathrm{wt}$ pct and is bainite (Figure 8). It is well known that steels with lower carbon content require higher cooling rates in order to obtain a martensitic structure. Thus, in the structure with the carbon inhomogeneities, for the same cooling rate during the quenching of the sample, it is possible to obtain martensite in the areas rich in carbon and bainite in the areas with lower carbon content. The formation of the "black" phase was noticed only on the former pearlite (which is austenite oversaturated with carbon) and proeutectoid ferrite (low in carbon) grain boundaries. Hence, the formation of bainite on cooling is possible.

\section{CONCLUSIONS}

1. Formation of the austenitic phase upon heating is possible in pearlite as well as in ferrite areas; however, in the first one, it proceeds at a much faster rate due to the shorter diffusion distances. The carbon content of the austenite nuclei formed on the ferrite-ferrite grain boundary is about $0.27 \mathrm{wt}$ pct, which is much lower than the equilibrium value determined by the metastable phase diagram. A possible explanation is proposed based on thermodynamic considerations for the formation of lowcarbon austenite (on ferrite-ferrite grain boundaries) and high-carbon austenite (on pearlite-ferrite grain boundaries).

2. Depending on the heating rate, the pearlite-to-austenite transformation can proceed in either one or two steps. At low heating rates $\left(0.05^{\circ} \mathrm{C} / \mathrm{s}\right)$, the ferrite and cementite plates transform simultaneously. At higher heating rates $\left(20^{\circ} \mathrm{C} / \mathrm{s}\right)$, a two-step process is observed: first ferrite within the pearlite grain transforms into austenite and then the dissolution of the cementite lamellae takes place.

3. Carbon inhomogeneities give rise to specific phenomena in the $\alpha / \gamma$ structure. The formation of finger-type austenite occurs on pearlite-ferrite grain boundaries and coincides with the position of cementite plates. In places where the direction of cementite lamellae is not perpendicular to the grain boundary, the formation of the "black" phase, which is believed to be bainite, takes place.

\section{ACKNOWLEDGMENTS}

This work is done within the framework of the research program of the Netherlands Institute for Metals Research (www.nimr.nl), Project No. MC5.03171. The authors thank Dr. Arjan Rijkenberg (Corus, the Netherlands) for performing the SEM measurements. 


\section{REFERENCES}

1. G.R. Speich, V.A. Demarest, and R.L. Miller: Metall. Trans. A, 1981, vol. 12A, pp. 1419-28.

2. M. Hillert, K. Nilsson, and L.E. Torndahl: J. Iron Steel Inst., London, 1971, vol. 209, pp. 49-66.

3. S.K. Jayaswal and S.P. Gupta: Metallkd., 1992, vol. 83, pp. 809 19.

4. C. Garcia de Andres, F.G. Caballero, and C. Capdevila: Scripta Mater., 1998, vol. 38 (12), pp. 1835-42.

5. V.I. Zel'dovich, I.V. Khomskaya, and O.S. Rinkevich: Phys. Met. Metallogr., 1992, vol. 73 (3), pp. 250-65.

6. N.C. Law and D.V. Edmonds: Metall. Mater. Trans. A, 1980, vol. $11 \mathrm{~A}$, pp. $33-46$

7. J.W. Christian: The Theory of Transformations in Metals and Alloys, Pergamon, Amsterdam, The Netherlands, 2002, pp. 422-79.

8. I.I. Novikov: Teoria Termicheskoi Obrabotki Metallov \{Theory of Heat Treatment of Metals\}, Metallurgia, Moskow, 1986, pp. 154 62.
9. S. Saunders, P. Karduck, and W.G. Sloof: Microchim. Acta, 2004, vol. 145 , pp. 209-13.

10. J.T. Armstrong: in Electron Probe Quantitation, K.F.J. Heinrich and D.E. Newbury, eds., Plenum Press, New York, NY, 1991, pp. 261-315.

11. G.A. Roberts and R.F. Mehl: Trans. ASM, 1943, Sept., pp. 613 50 .

12. G.R. Speich, A. Szirmae, and M.J. Richards: Trans. TMS-AIME, 1969, vol. 245, pp. 1063-74.

13. C.R. Brooks: Principles of the Austenitization of Steels, Elsevier Applied Science, London, 1992, pp. 81-144.

14. A. Jacot, M. Rappaz, and R.C. Reed: Acta Mater., 1998, vol. 46, pp. 3949-62.

15. L.E. Samuels: Optical Microscopy of Carbon Steels, ASM, Metals Park, OH, 1980, pp. 101-498.

16. D.A. Porter and K.E. Easterling: Phase Transformations in Metals and Alloys, 2nd ed., Nelson Thornes Ltd., Cheltenham, United Kingdom, 2001, pp. 171-80. 